\title{
Ultrastructure of spermiogenesis and spermatozoa of Discocotyle sagittata (Monogenea: Polyopisthocotylea: Discocotylinea)
}

\author{
Joanne Cable ${ }^{1,2}$ and Richard C. Tinsley ${ }^{1}$ \\ ${ }^{1}$ School of Biological Sciences, University of Bristol, Woodland Rd., Bristol BS8 1UG, UK; \\ ${ }^{2}$ Present address: School of Biosciences, Main Building, Cardiff University, Cardiff CF10 3TL, UK
}

Key words: Platyhelminthes, TEM, fluorescent nuclear labelling, spermatogenesis, spermatozoon

\begin{abstract}
Ultrastructural analysis revealed that the spermatozoon of Discocotyle sagittata (Leuckart, 1842) is composed of two parallel axonemes, mitochondrion, nucleus and cortical microtubules. The nucleus, which occupies a central/distal position and has an unusual crescent-shaped profile, is slightly shorter than the mitochondrial rod. The two axonemes, which are of unequal length, and the cortical microtubules (up to 68 forming a continuous ring in the principal region) extend almost the entire length of the spermatozoon. A fold of the plasma membrane creates a unilateral flange or undulating membrane. Epifluorescence microscopy indicated that spermatogenesis gives rise to clusters of 64 spermatids connected to a common cytophore. Spermiogenesis and the structure of the filiform sperm of $D$. sagittata conform to the typical polyopisthocotylean pattern.
\end{abstract}

Comparative spermatology has contributed greatly to interpretation of platyhelminth phylogeny. Ultrastructural studies have identified distinct patterns of spermatogenesis amongst higher taxa and morphological variations in sperm structure have been used to distinguish species (reviews by Justine 1991a, b, 1993a). More recently, fluorescent dyes and antibodies which stain the nucleus and axial units have proved invaluable for interpreting the long filiform structure of spermatozoa and the processes involved in gametogenesis (e.g. Harris et al. 1997, Iomini et al. 1997, Raikova and Justine 1999). Within the Monogenea, most variation in sperm structure occurs within the Monopisthocotylea (three distinct patterns) and there is much greater uniformity amongst the Polyopisthocotylea (a single pattern with minor variations described by Justine 1993a). For comprehensive phylogenetic studies, it is important to extend the number of species analysed (Justine 1993b). Polyopisthocotylean sperm morphology has been examined in taxa representative of 17 of the 32 families recognised by Boeger and Kritsky (1993) (see Justine 1995). However, among the Discocotylinea, sperm structure has only been examined in two of the six families, and this includes the highly aberrant aflagellate sperm of Diplozoon gracile, in addition to the more typical sperm of Diclidophora merlangi and Choricotyle pagelli (review in Justine 1995). The current study assesses formation and structure of spermatozoa of Discocotyle sagittata (Leuckart, 1842) using fluorescence and transmission electron microscopy, thereby extending knowledge of the suborder to include the Discocotylidae.

Discocotyle sagittata is an oviparous, blood-feeding, polyopisthocotylean monogenean infecting the secon- dary gill lamellae of trout (Salmo trutta and Oncorhynchus mykiss in the UK). Recent research has focused on egg production, development, hatching and larval survival of this parasite (Gannicott and Tinsley 1997, 1998a, b); the only structural studies have been limited to light microscope observations (Timofeeva 1986, Cable et al. 1996).

\section{MATERIALS AND METHODS}

Adult Discocotyle sagittata were recovered from the gills of rainbow trout, Oncorhynchus mykiss (Walbaum), originating from the Government Fish Hatchery, Cornaa, Isle of Man and maintained in the aquarium at Bristol.

Epifluorescence microscopy. Living worms were transferred from dechlorinated water into a freshly prepared 1$5 \mu \mathrm{g} / \mathrm{ml}$ solution of bisBenzimide (Hoechst 33258, Sigma) containing $1-5 \%$ acetic acid. Individual parasites were teased apart with insect pins and the posterior region of the body containing the testes was transferred using a fine bristle to a drop of the stain-fixative on a microscope slide. The tissue was squashed by applying uniform pressure to a coverslip and examined using a Nikon Optiphot fluorescence microscope, with $330-380 \mathrm{~nm}$ excitation and $420 \mathrm{~nm}$ barrier filters.

Transmission electron microscopy (TEM). Additional specimens were fixed at $4{ }^{\circ} \mathrm{C}$ in $2.5 \%$ glutaraldehyde buffered with $0.1 \mathrm{M}$ sodium cacodylate for $4 \mathrm{~h}$, washed overnight in the same buffer, and post-fixed for $10 \mathrm{~min}$ in cacodylate buffered $1 \%$ osmium tetroxide. The worms were then rinsed briefly in buffer and cut into $5 \mathrm{~mm}$ transverse strips before being returned to fresh osmium tetroxide and fixed for a further $1 \mathrm{~h}$. Subsequently, the tissue was rinsed, dehydrated and embedded in Araldite resin. Ultrathin sections from 11 adult worms were double stained with uranyl acetate and lead citrate and viewed on a JEOL 1200 EX or 1210 electron microscope operated at $80 \mathrm{kV}$. 


\section{RESULTS}

The testes of Discocotyle sagittata are extensive and consist of numerous oval follicles located in the posterior half of the body between the intestinal caeca. Peripheral testis follicles are interspersed with intricate gut branches. Each follicle is surrounded by fine layers of electron-dense strands, possibly connective tissue or nerve fibres (Figs. 1A, B). All stages of spermatogenesis were found in any one follicle.

\section{Spermatogenesis}

Spermatogonia are often compressed at the periphery of each follicle. These dense, often elongate-ovate, cells are characterised by a very high nucleo-cytoplasmic ratio (Fig. 1A). Primary and secondary spermatocytes are located in deeper regions of the testicular follicles (Figs. 1A, C) surrounded by whorls or ribbons of mature spermatozoa, and occasional isolated sperm (Figs. 1, 2D). Spermatocytes have granular cytoplasm and contain much endoplasmic reticulum (ER) and vacuoles. The nucleus is electron-lucent with spherical clusters of chromatin. The cells are so tightly compressed that it was not possible to discern individual clusters of spermatogonia. However, staining with bisBenzimide and fluorescence light microscopy indicated that up to 64 differentiating spermatids are connected by a single cytophore (Figs. 2A, B). The number of spermatids in a cluster ranged from 52 to 64 , but this variation is probably the result of clusters being disrupted during tissue flattening.

\section{Spermiogenesis}

The nucleo-cytoplasmic ratio of early spermatids is lower than in spermatocytes and the nuclei have prominent pores in their envelope. Mitochondria are greatly enlarged with short cisternae and they may contain lamellar whorls. Sheets of ER and free ribosomes are abundant in the electron-lucent granular cytoplasm (Fig. 3A). During spermiogenesis, conformational changes occur in the chromatin and nucleus shape (Fig. 3B). The nucleus decreases in volume, chromatin condenses into lamellae which become organised into scroll-like twisted configurations interspersed with interchromatin granules (Fig. 3C). Simultaneous with nuclear elongation, a cone-shaped projection appears at the cell periphery which contains much electron-dense material (Fig. 3B), including fine dense rods that may be modified microtubules. Further elongation of this outgrowth in the zone of differentiation (ZD) results in formation of the spermatozoan cell body. Mitochondria aggregate at the base of the $\mathrm{ZD}$, fuse together and extend into the developing cone. The projection grows outward and its base sinks into the underlying cytoplasm, forming a shallow ring-like groove delimited by arching membranes. Free ribosomes occur in the projection but no ER or Golgi cisternae were observed.
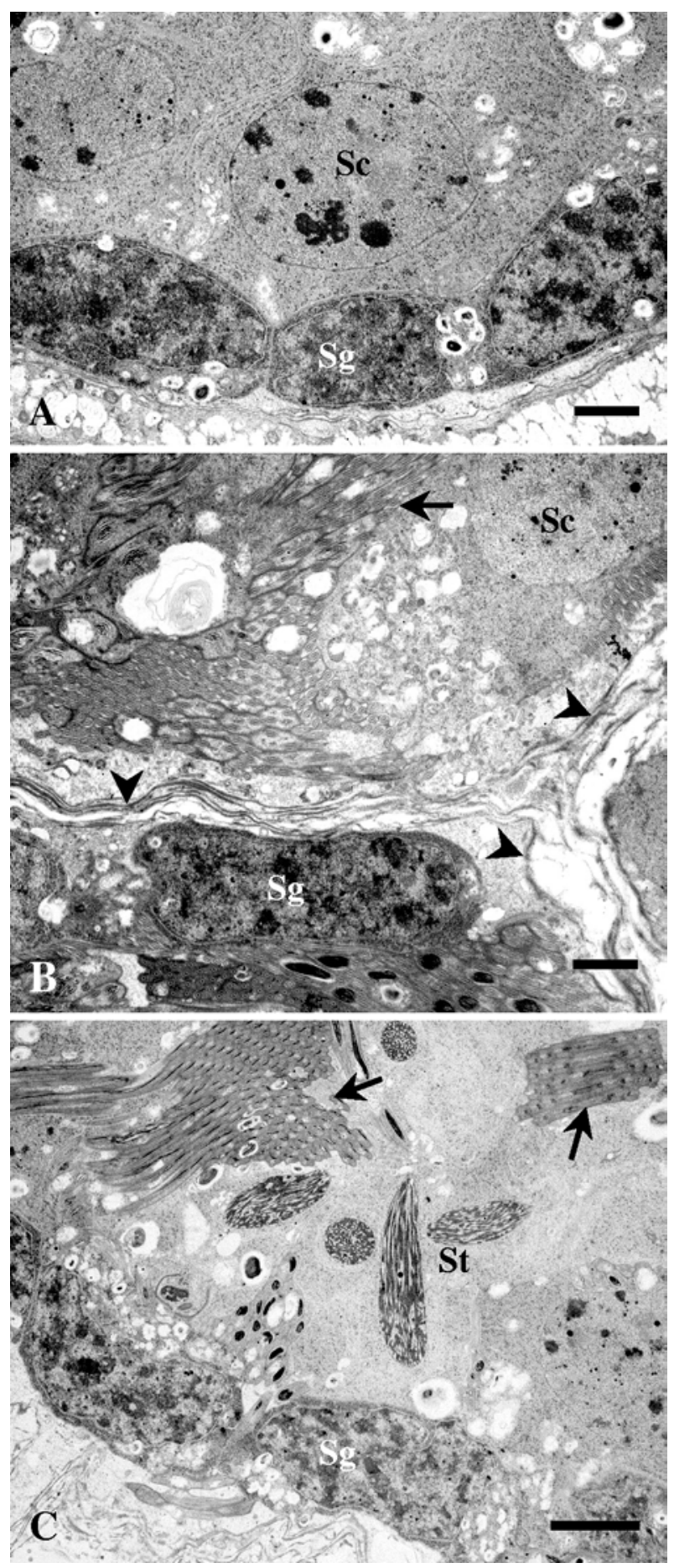

Fig. 1. Spermatogenesis of Discocotyle sagittata. Putative connective tissue or nerve fibres surrounding each testis follicle (arrowheads). Spermatogonia (Sg) at the testis periphery, whereas spermatocytes (Sc), spermatids (St) and whorls of mature spermatozoa (arrows) tend to lie internally. Scale bars: $A, B=2 \mu \mathrm{m} ; C=4 \mu \mathrm{m}$. 


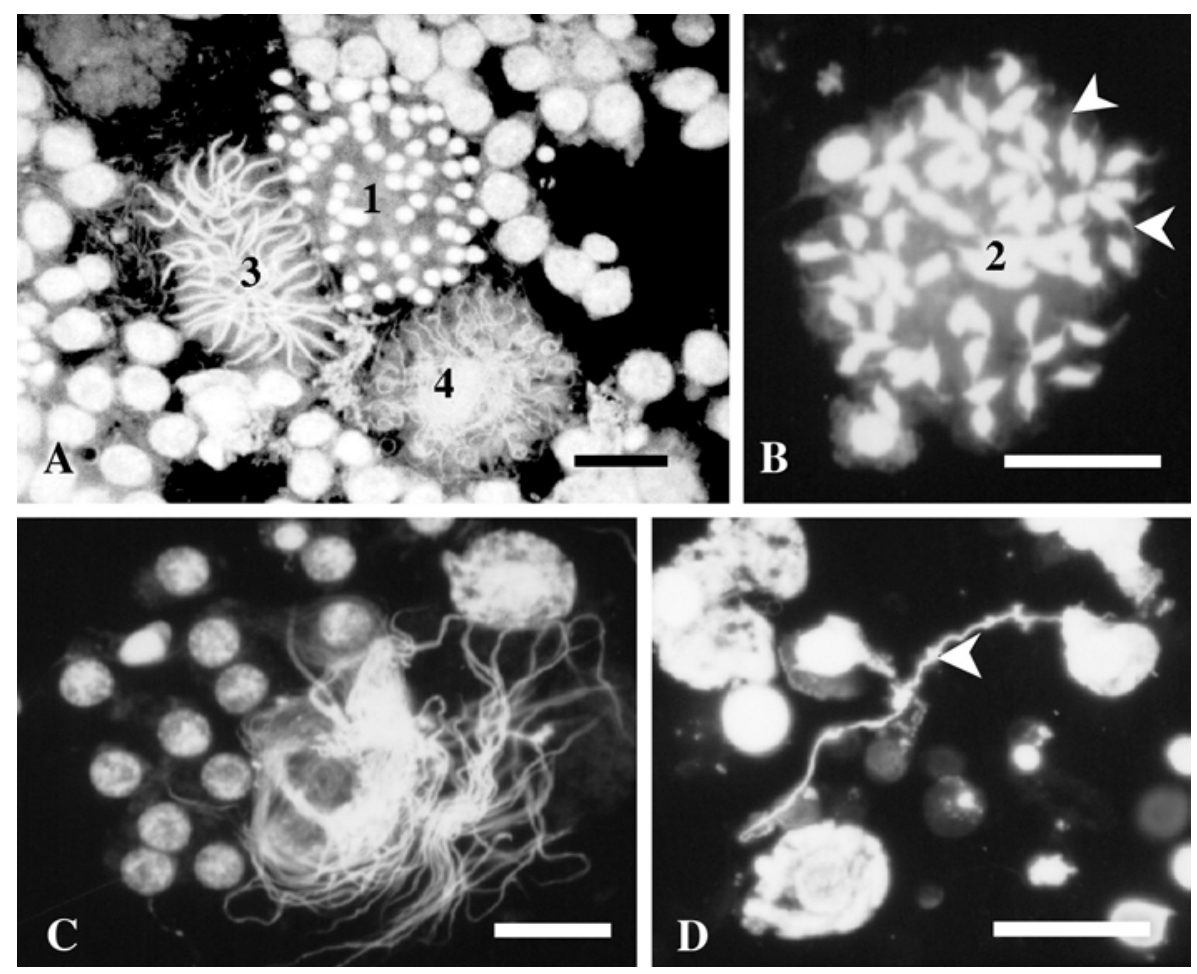

Fig. 2. Stages of spermatogenesis in flattened preparations of the testes of Discocotyle sagittata stained with bisBenzimide. A, B - Cluster of early spermatids with rounded nuclei (1) and developing spermatids with nuclei in the initial stages of elongation (2). Chromatin condensation is most apparent at the extending tip of the nuclei (arrowheads) which project towards the periphery of the cluster. Late-stage spermatids with uniformly thickened nuclei (3) which subsequently condense into fine filiform strands (4) that are still connected to a central cytophore. C - Bundle of recently formed sperm. D - Individual nucleus of mature sperm (arrowhead). Scale bars: A, B $=40 \mu \mathrm{m} ; \mathrm{C}, \mathrm{D}=20 \mu \mathrm{m}$.

Microtubules become apparent at the leading edge of the $\mathrm{ZD}$ into which projects the extending tip of the nucleus (Figs. 3B, D). Two basal bodies develop either side of an intercentriolar (or central) body (ICB). This consists of one central and two outer electron-dense layers separated by fine cross-striations which create the appearance of two fused, parallel, ladders, ca. $0.25 \times 0.5$ $\mu \mathrm{m}$ (Fig. 4A). From the basal bodies develop proximal tapered striated rootlets which extend through the ZD into the cytophore. Axonemes $(9+$ " 1 " microtubule arrangement) develop from the basal bodies to form lateral processes. Initially, the basal bodies are perpendicular to the ICB as indicated by the lateral positions of the striated rootlets and axonemes, but they rotate so the rootlets and flagella come to lie almost parallel (Fig. $4 B$ ) and eventually fuse with the developing sperm body. The spermatids are pinched off from the cytophore at the level of the arching membranes. The basal bodies, ICB and rootlets which were not observed in mature spermatozoa, presumably withdraw into the cytophore.

\section{Mature spermatozoa}

The filiform sperm of $D$. sagittata conforms to the typical polyopisthocotylean pattern, composed of two parallel axonemes, mitochondrion, nucleus and cortical microtubules. There was no evidence to suggest that the elongate mitochondrion is not a single structure. Examination of cross-sections from the seminal vesicle provided the basis for a reconstruction of sperm ultrastructure (Fig. 5). The distal (or posterior) region is characterised by electron-dense plaques (Figs. 5I, J). These plaques represent attachment zones where the axonemes are incorporated into the sperm body during spermiogenesis (e.g. Justine and Mattei 1985). In the principal region of the spermatozoon, the nucleus which is crescent-shaped with a central bulge on its concave surface, partially surrounds the axonemes (Fig. 5H). The nuclear chromatin is densely packed and the nuclear membranes are irregular, often enclosing a large perinuclear space. No pores were detected in the nuclear envelope. The nucleus is $65-70 \mu \mathrm{m}$ long (Fig. 2D) and cross-sectional profiles indicate that it is slightly shorter than the mitochondrial rod. The mitochondrion extends beyond the nucleus proximally and to a greater extent at the distal end of the spermatozoon. Two axonemes extend the majority of the length of the spermatozoon, but they are of slightly unequal length, one extending further at the proximal end. Each axoneme consists of 9 paired microtubules surrounding a central core. Radial spokes connect the axoneme core to the A-microtubule which is characterised by the presence of dynein arms. 

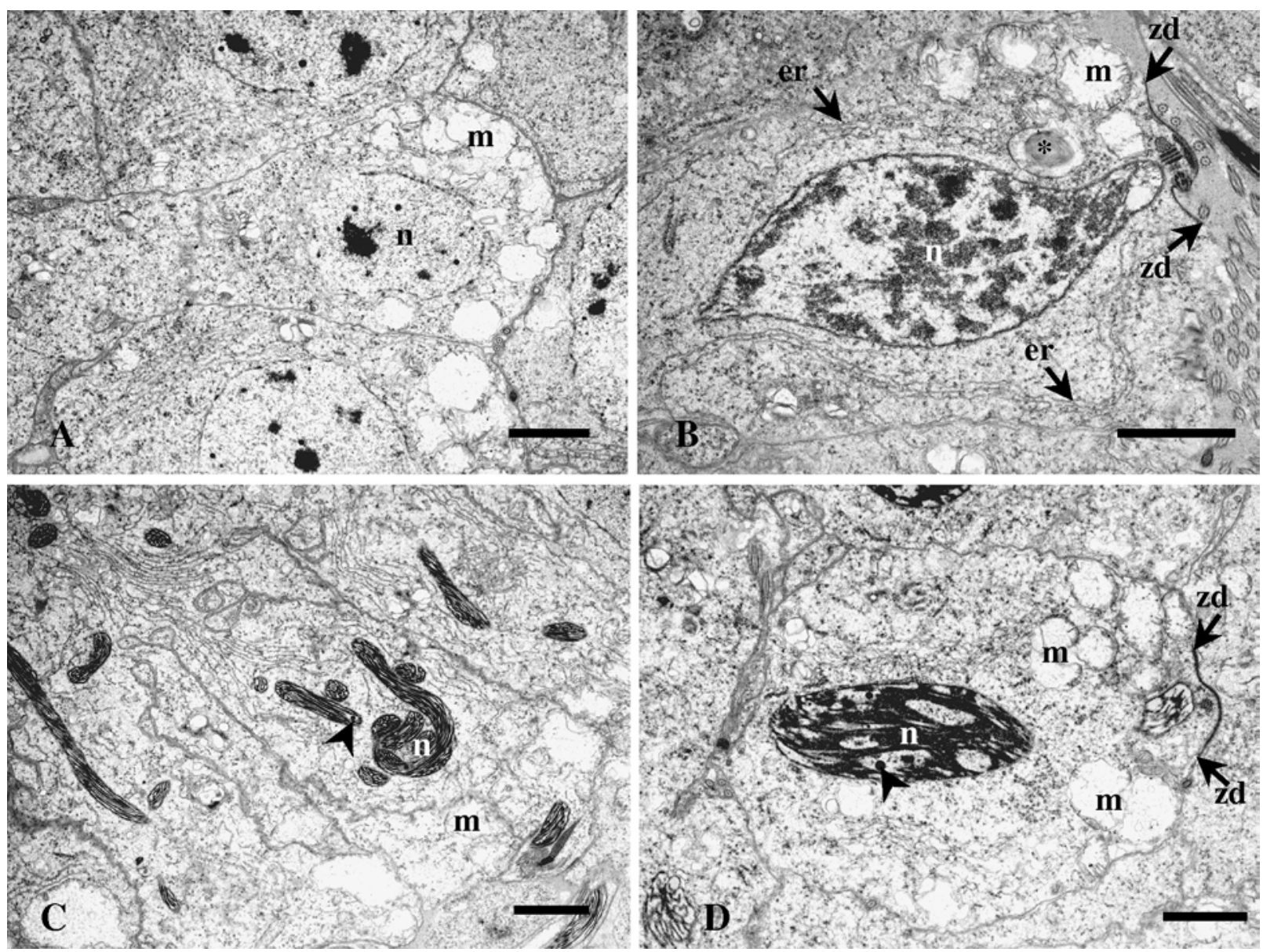

Fig. 3. Spermiogenesis of Discocotyle sagittata. A - Early spermatid with prominent nucleus (n) and enlarged mitochondria (m) clustered to one pole of the cell. $\mathbf{B}$ - Spermatid nucleus undergoing initial stages of elongation, equivalent stage to that shown in Fig. 2B. Endoplasmic reticulum (er), free ribosomes and numerous vesicles fill the granular cytoplasm. Mitochondria may contain lamellar bodies $\left(^{*}\right)$. Aggregation of dense material in the developing zone of differentiation (zd). C, D - Spermatids undergoing nuclear condensation. Interchromatin granules (arrowheads) amongst the characteristic scroll-like configurations of chromatin, and thickened plasma membrane delimits the zone of differentiation (zd). Scale bars $=2 \mu \mathrm{m}$.

Cortical microtubules extend the length of the spermatozoon; each appears connected to the cell plasma membrane by a single short electron-dense rod. The number of microtubules ranged from 24 at one extremity through 22-34 surrounding 2 axonemes with/ without mitochondrion, to 51-55 in the principal region, with up to 68 in the distal region with the largest nucleus profile. With the exception of the distal end, the cortical microtubules tend to form a complete ring but this is disrupted by the presence of peripheral electrondense plaques (Figs. 5I, J). Some spermatozoa profiles containing the nucleus, mitochondrion, both axonemes and complete ring of microtubules (52-64), were observed with a lateral flange (Fig. 5E). This protuberance, ca. $450 \times 50 \mathrm{~nm}$, formed from a fold of the plasma membrane, did not exhibit any external ornamentation. The flange was observed on either the left or right side of each spermatozoon, but no bilateral projections were recorded.

Many disintegrating spermatozoa were detected in the seminal vesicle and vas deferens, but there was no evidence of structural abnormalities, such as multiple axonemes.

\section{DISCUSSION}

Spermiogenesis and the basic structure of the mature sperm of Discocotyle sagittata conforms to the pattern found in other polyopisthocotylean monogeneans, digeneans and aspidogastreans. Typically, spermiogenesis involves: 1) formation of zones of differentiation on the cytophore surface, characterised by two free flagella derived from basal bodies, 2) elongation of the nucleus and mitochondrion into the developing sperm body and 


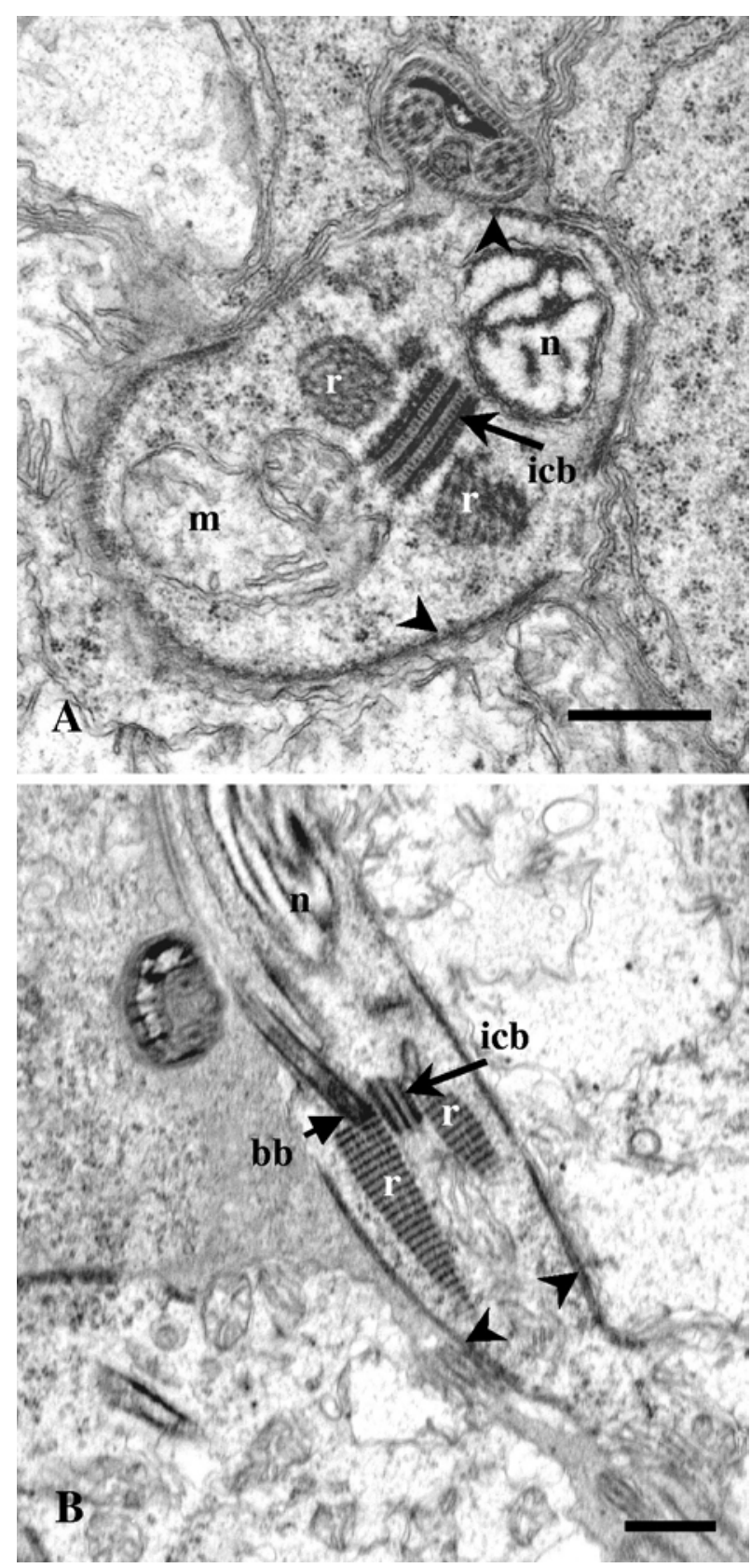

Fig. 4. Spermiogenesis of Discocotyle sagittata. A Transverse section through the zone of differentiation containing the nucleus (n), mitochondrion/ia (m), the intercentriolar body (icb), lateral roots (r) and cortical microtubules (arrowheads). B - Late spermatid with striated rootlets ( $\mathrm{r}$ ), basal bodies ( $\mathrm{bb}$ ) and axonemes either side of the intercentriolar body (icb) parallel within the main cell body. Scale bars $=0.5 \mu \mathrm{m}$.

formation of an intercentriolar body, 3) rotation of the basal bodies and striated rootlets, bringing the axonemes parallel to the sperm body, with which they subsequently fuse, and 4) release of filiform spermatozoa from the disintegrating cytophore. Justine (1991a) described this state as a synapomorphy of the Poly- opisthocotylea. The gametes of $D$. sagittata presumably undergo the typical mitotic and meiotic cell divisions producing 64 spermatids from each cluster. The number of spermatids produced during each cycle of spermatogenesis is variable among monogeneans but it is 64 in most species (Justine et al. 1993, Watson 1997).

Examination of sperm structure in D. sagittata indicates plesiomorphy within the Discocotylinea, with the notable exception of Diplozoon gracile (review Justine 1995). This supports previous data which negate the potential use of sperm structure for phylogenetic studies among the Polyopisthocotylea, but comparative studies are still important as they may shed light on functional biology (Justine 1995). Nuclear location in parasitic platyhelminths is a matter of controversy, but the nucleus tends to be described as posterior as this region is last to enter the oocyte during fertilisation (Justine 1995, Justine and Mattei 1984, 1986). Alternatively, the antero-posterior orientation of spermatozoa is expressed in proximal-distal terms, the distal tip of the spermatid defined during spermiogenesis with respect to the cytophore (e.g. Ishida et al. 1991). The nucleus of $D$. sagittata sperm has a central to distal (posterior) location. The unusual transverse profile of the nucleus which partially surrounds the axial units is also found in Concinnocotyla australensis and various cestodes (Watson et al. 1995 and references), but the functional benefits of this particular morphology are unknown. In D. sagittata, as in Bucephaloides gracilescens (see Erwin and Halton 1983), the mitochondrial rod of each spermatozoon extends distally and proximally beyond the nucleus. However, the two species differ in their position of the axonemes. In D. sagittata, the ends of both axial units are proximally located with respect to the nucleus, whereas in B. gracilescens one axoneme lies alongside the distal end of the mitochondrion.

Undulating membranes are found in the polyopisthocotyleans Concinnocotyla australensis (see Watson et al. 1995), Gotocotyla acanthura (see Justine and Mattei 1985), Gonoplasius sp. (see Rohde and Watson 1994), and in the aspidogastreans Multicotyle purvisi (see Watson and Rohde 1995) and Lobatostoma manteri (see Rohde et al. 1991). In the monopisthocotylean Macrogyrodactylus polypteri, the mid-region spermatozoon bears a prominent lateral protrusion with microtubules, similar in appearance to an undulating membrane, but it contains at its tip the mitochondrion (Schmahl and Elwasila 1992). A lateral flange most similar to that in Concinnocotyla also occurs in the digenean Echino-stoma caproni (see Iomini and Justine 1997). In the current study, a similar membrane was detected in the central region of $D$. sagittata sperm, but the relative infrequency of encountering these crosssectional profiles indicates that the undulating membrane is restricted to a relatively short region of the spermatozoan. Watson et al. (1995) suggested that the 


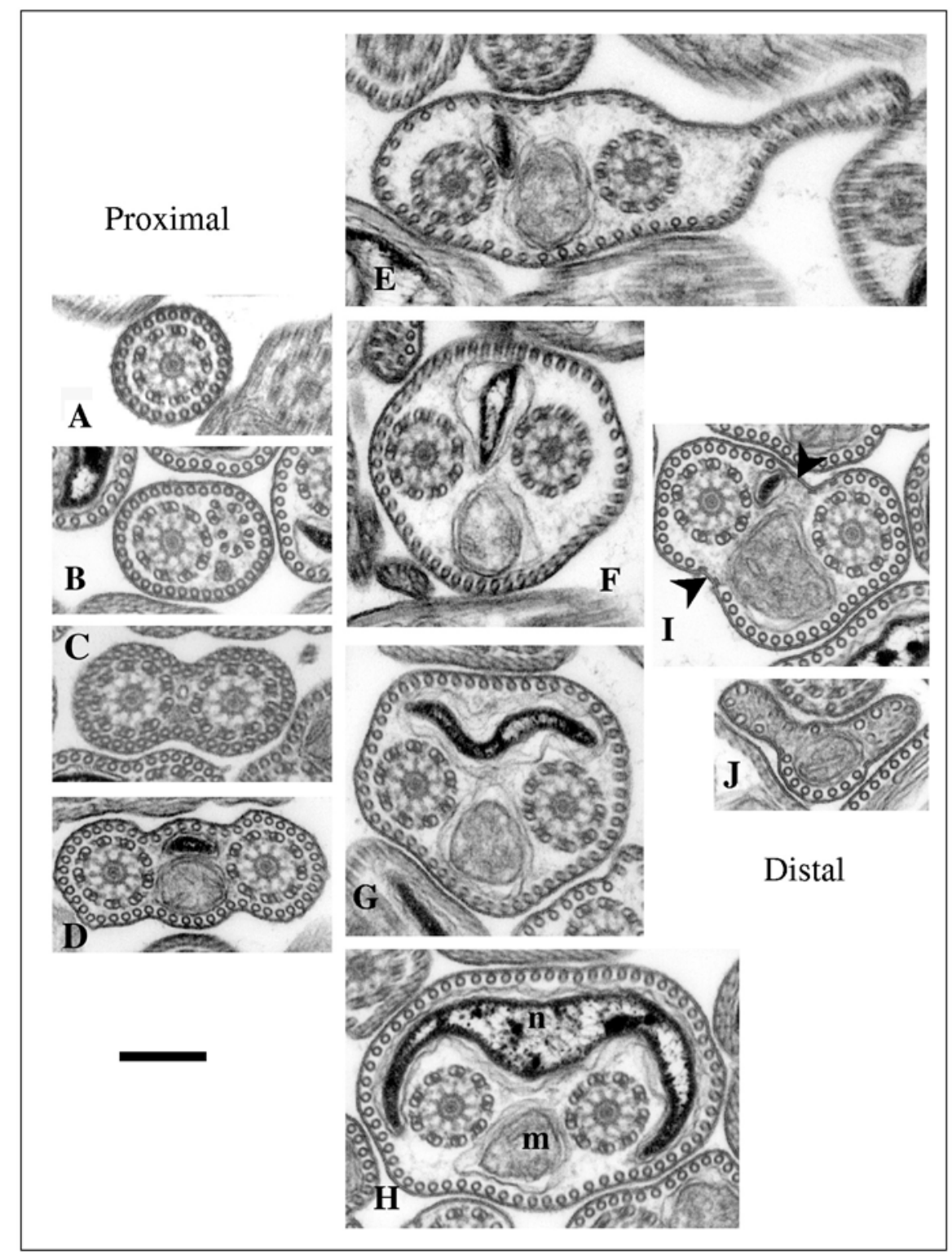

Fig. 5. Cross-sections of mature sperm of Discocotyle sagittata. A - Proximal, single axial unit with $9+$ "1" structure surrounded by cortical microtubules. Each doublet with dynein arms is connected to the central core by short radial spokes. B Microtubules at the tip of the second (shorter?) axoneme. C - Tip of the mitochondrion and nucleus between the two axonemes. $\mathbf{D}$ - Two axonemes, mitochondrion slightly larger in cross-section compared to the nucleus. $\mathbf{E}$ - Fold of the plasma membrane forming the lateral flange. $\mathbf{F}$ - Axial units, mitochondrion and nucleus, all of similar cross-sectional diameters. $\mathbf{G}-$ Elongated nucleus, mitochondrion and axial units. $\mathbf{H}$ - Crescent-shaped nucleus partially surrounding the mitochondrion and axonemes. I Distal tip of nucleus, mitochondrion and two axonemes. $\mathbf{J}$ - Distal tip of mitochondrion. Note cortical microtubules extend the length of the sperm; nucleus (n); mitochondrion (m); attachment zones (arrowheads). Scale bar $=0.2 \mu \mathrm{m}$.

position of undulating membranes might be of phylogenetic significance. However, in D. sagittata the flange occurs on either the right or left side. The undulating membrane of platyhelminth sperm probably contributes to spermatozoan mobility (Justine and Mattei 1985).

Unusually, in D. sagittata, there is a plexus of cholinergic fibres associated with the testes (Cable et al. 1996). No such innervation has been reported in the male reproductive system of any other platyhelminth and its role is unknown. Putative nerve fibres were observed around the testis follicles in the current study, but they were unusually compressed, lacked the typical neurosecretory vesicles (e.g. Halton et al. 1991) and could not be traced back to any cell bodies. It was therefore not possible to identify this tissue, but its distribution corresponded with the nerve plexus previously observed from light microscopy (Cable et al. 1996). 
Epifluorescence light microscopy has contributed to this electron microscopy study by demonstrating the stages of spermatogenesis. Although not previously tested in platyhelminths, the mitochondrial rod (in addition to the nucleus and axial units) could also be fluor-labelled to obtain a complete 3-D image of sperm structure without TEM serial sections. In addition, fluorescent dyes have proved useful for rapidly screening individual gyrodactylid parasites for evidence of insemination (Harris et al. 1997, unpublished). As Gyrodactylus species are small, thin worms (less than 1 $\mathrm{mm}$ in length and can be flattened to only a few cells thickness under a coverslip), epifluorescence can detect all sperm within an individual (Harris et al. 1997). However, fluorescent dyes could be used to map sperm distribution in larger parasites. If used in conjunction with confocal scanning laser microscopy, fluorescent markers would not be restricted by the thickness of parasite tissue.

Acknowledgements. This work was funded by research grants GR3/09010 and GR3/10563 from the Natural Environment Research Council, UK.

\section{REFERENCES}

BOEGER W.A., KRITSKY D.C. 1993: Phylogeny and a revised classification of the Monogenoidea Bychowsky, 1937 (Platyhelminthes). Syst. Parasitol. 26: 1-32.

CABLE J., MARKS N.J., HALTON D.W., SHAW C., JOHNSTON C.F., TINSLEY R.C., GANNICOTT A.M. 1996: Cholinergic, serotoninergic and peptidergic components of the nervous system of Discocotyle sagittata (Monogenea: Polyopisthocotylea). Int. J. Parasitol. 26: 1357-1367.

ERWIN B.E., HALTON D.W. 1983: Fine structural observations on spermatogenesis in a progenetic trematode, Bucephaloides gracilescens. Int. J. Parasitol. 13: 413-426.

GANNICOTT A.M., TINSLEY R.C. 1997: Egg hatching in the monogenean gill parasite Discocotyle sagittata from the rainbow trout (Oncorhynchus mykiss). Parasitology 114: 569-579.

GANNICOTT A.M., TINSLEY R.C. 1998a: Larval survival characteristics and behaviour of the gill monogenean Discocotyle sagittata. Parasitology 117: 491-498.

GANNICOTT A.M., TINSLEY R.C. 1998b: Environmental effects on transmission of Discocotyle sagittata (Monogenea): egg production and development. Parasitology 117: 499-504.

HALTON D.W., BRENNAN G.P., MAULE A.G., SHAW C., JOHNSTON C.F., FAIRWEATHER I. 1991: The ultrastructure and immunogold labelling of pancreatic polypeptide-immunoreactive cells associated with the eggforming apparatus of a monogenean parasite, Diclidophora merlangi. Parasitology 102: 429-436.

HARRIS P.D., CABLE J., TINSLEY R.C. 1997: Detection of sperm within Gyrodactylus (Platyhelminthes, Monogenea) tissues using fluorescence and transmission electron microscopy. Parasitol. Res. 83: 533-538.

IOMINI C., JUSTINE J.-L. 1997: Spermiogenesis and spermatozoon of Echinostoma caproni (Platyhelminthes, Digenea): transmission and scanning electron microscopy, and tubulin immunocytochemistry. Tissue Cell 29: 107118.

IOMINI C., MOLLARET I., ALBARET J.-L., JUSTINE J.-L. 1997: Spermatozoon and spermiogenesis in Mesocoelium monas (Platyhelminthes, Digenea): ultrastructure and epifluorescence microscopy of labelling of tubulin and nucleus. Folia Parasitol. 44: 26-32.
ISHIDA S., YAMASHITA Y., TESHIROGI W. 1991: Analytical studies of the ultrastructure and movement of the spermatozoa of freshwater triclads. Hydrobiologia 227: 95-104.

JUSTINE J.-L. 1991a: Cladistic study of the Monogenea (Platyhelminthes), based upon a parsimony analysis of spermiogenetic and spermatozoal characters. Int. J. Parasitol. 21: 821-838.

JUSTINE J.-L. 1991b: Spermatozoa as a tool for taxonomy of species and supraspecific taxa in the Platyhelminthes. In: B. Baccetti (Ed.), Comparative Spermatology 20 Years After. Raven Press, New York, pp. 981-984.

JUSTINE J.-L. 1993a: Phylogénie des Monogènes basée sur une analyse de parcimonie des caractères de l'ultrastructure de la spermiogénèse et des spermatozoïdes incluant les résultats récents. Bull. Fr. Pêche Piscic. 328: 137-155.

JUSTINE J.-L. 1993b: Ultrastructure of the Monogenea: lists of investigated species and organs. Bull. Fr. Pêche Piscic. 328: 156-188.

JUSTINE J.-L. 1995: Spermatozoal ultrastructure and phylogeny of the parasitic platyhelminthes. In: B.G.M. Jamieson, J. Ausió and J.-L. Justine (Eds.), Advances in Spermatozoal Phylogeny and Taxonomy. Mém. Mus. Natl. Hist. Nat. 166: 55-86.

JUSTINE J.-L., AFZELIUS B.A., MALMBERG G., MATTEI X. 1993: Ultrastructure of spermiogenesis in Acantho-cotyle and Myxinidocotyle (Platyhelminthes, Monogenea, Acanthocotylidae). Acta Zool. (Stockh.) 74: 119-126.

JUSTINE J.-L., MATTEI X. 1984: Ultrastructural observations on the spermatozoon, oocyte and fertilization process in Gonapodasmius, a gonochoristic trematode (Trema-toda: Digenea: Didymozoidae). Acta Zool. (Stockh.) 65: 171-177.

JUSTINE J.-L., MATTEI X. 1985: A spermatozoon with undulating membrane in a parasitic flatworm, Gotocotyla (Monogenea, Polyopisthocotylea, Gotocotylidae). J. Ultrastruct. Res. 90: 163-171.

JUSTINE J.-L., MATTEI X. 1986: Ultrastructural observations on fertilization in Dionchus remorae (Platyhelminthes, Monogenea, Dionchidae). Acta Zool. (Stockh.) 67: 97-101. 
RAIKOVA O.I., JUSTINE J.-L. 1999: Microtubular system during spermatogenesis and in the spermatozoon of Convoluta saliens (Platyhelminthes, Acoela): tubulin immunocytochemistry and electron microscopy. Mol. Reprod. Dev. 52: 74-85.

ROHDE K., WATSON N.A. 1994: Spermiogenesis in Gonoplasius sp. (Platyhelminthes, Monogenea, Polyopisthocotylea, Microcotylidae). Acta Parasitol. 39: 111116.

ROHDE K., WATSON N.A., CRIBB T. 1991: Ultrastructure of sperm and spermatogenesis of Lobatostoma manteri (Trematoda, Aspidogastrea). Int. J. Parasitol. 21: 409-419.

SCHMAHL G., ELWASILA M. 1992: Fine structure of spermatogenesis in monopisthocotylean monogeneans (Macrogyrodactylus polypteri, Pseudodactylogyrus bini). Folia Parasitol. 39: 19-31.
TIMOFEEVA T.A. 1986: The nervous system of Discocotyle sagittata and Axine belones (Monogenea, Mazocraeidae). Tr. Zool. Inst. Akad. Nauk SSSR. Morfol. Sist. Faunist. Parazit. Zhiv. 155: 41-49. (In Russian.)

WATSON N.A. 1997: Spermiogenesis and sperm ultrastructure in Troglocephalus rhinobatidis, Neoheterocotyle rhinobatidis and Merizocotyle australensis (Platyhelminthes, Monogenea, Monopisthocotylea, Monocotylidae). Int. J. Parasitol. 27: 389-401.

WATSON N.A., ROHDE K. 1995: Re-examination of spermiogenesis of Multicotyle purvisi (Platyhelminthes, Aspidogastrea). Int. J. Parasitol. 25: 579-586.

WATSON N.A., WHITTINGTON I.D., ROHDE K. 1995: Ultrastructure of spermiogenesis and spermatozoa in the monogeneans Concinnocotyla australensis (Polystomatidae) and Pricea multae (Gastrocotylidae). Parasite 1995: 357-366.

Accepted 29 March 2001 